\title{
Prognostic value of molecular markers and cytogenetic alterations that characterize breast cancer precursor lesions (Review)
}

\author{
MAURIZIO DI BONITO, MONICA CANTILE, ROSSELLA DE CECIO, GIUSEPPINA LIGUORI and GERARDO BOTTI
}

Pathology Unit, National Cancer Institute, INT Pascale Foundation, Naples I-80131, Italy

Received April 18, 2013; Accepted July 1, 2013

DOI: $10.3892 / \mathrm{ol} .2013 .1589$

\begin{abstract}
The understanding of the molecular mechanisms that underlie all stages of tumor progression in breast cancer (BC) represents an important goal in the biomedical research of this disease, particularly for the identification of more specific targeted therapies. In this context, BC preinvasive and precursor lesions represent a major dilemma. These lesions are well characterized under the phenotypic and genotypic profile, but it is not clear if they represent obligatory passages of a multistep process determining breast cancer evolution. In fact, the numerous cytogenetic and molecular alterations identified are not always representative of the progression into invasive phenotypes.
\end{abstract}

\section{Contents}

1. Introduction

2. Cytogenetic and molecular alterations in precursor lesions

3. Conclusions

\section{Introduction}

Preinvasive and premalignant lesions of the breast are defined as 'precursor lesions' and represent a group of extremely heterogeneous lesions that have yet to be clearly classified. In addition, the risk of the neoplastic evolution of the lesions is not yet completely known. At present, these lesions are defined only as 'risk indicators' for breast cancer (BC), i.e. lesions with a variable potential to progress to malignant phenotypes. BC precursor lesions include atypical ductal hyperplasia (ADH), atypical lobular hyperplasia (ALH), columnar cell lesions (CCLs), ductal carcinoma in situ (DCIS), flat epithelial atypia

Correspondence to: Dr Monica Cantile, Pathology Unit, INT Pascale Foundation, via M Semmola, Naples I-80131, Italy E-mail: monicantile@libero.it

Key words: breast cancer precursor lesions, molecular alterations, tumor progression
(FEA), usual ductal hyperplasia (UDH) and lobular carcinoma in situ (LCIS) (1).

The molecular and morphological features of these lesions are indicative of a multistep model of breast tumorigenesis that provides a transition from normal epithelium to invasive carcinoma (1). Sequential steps differ according to whether the progenitor cells originate from the ducts or lobules: Ducts, UDH vs. FEA vs. ADH vs. DCIS vs. IDC (invasive ductal carcinoma); and lobules, HL vs. ALH vs. LCIS vs. ILC (invasive lobular carcinoma; Fig. 1) (1).

Consistent with the 'clonal evolution' hypothesis, there are numerous studies that show common genetic alterations among the precursors of low-grade BC (low-grade DCIS and $\mathrm{ADH})(2)$.

However, it has also been shown that these lesions do not have the same probability for progression into invasive carcinoma (3).

Recently, as a result of the use of specific and sophisticated technologies, a wide range of molecular alterations associated with preneoplastic forms have been identified. Although they represent a 'risk of evolution', their real diagnostic and prognostic value remains unclear.

\section{Cytogenetic and molecular alterations in precursor lesions}

Genotypic-phenotypic potential correlations are consistent with the hypothesis of a multistep evolution of precursor lesions. Several allelic imbalances have been identified in CCLs, located at 3p, 9p, 10q, 11q, 16q, 17p and 17q (4). Moreover, a number of copy number alterations have been described, including the loss of $16 \mathrm{q}$ and chromosome $\mathrm{X}$ and the gain of 15q, 16p, 17p and 19q (5). ALH and LCIS have a number of common cytogenetic abnormalities, in particular, the loss of $16 q, 16 p$ and $17 p$ and the gain of $6 q(6)$.

In addition, ADH and DCIS exhibit extremely similar cytogenetic patterns consistent with the hypothesis of progression. These cytogenetic abnormalities largely involve the loss of $16 q$ and $17 p$ and the gain of $1 q$ (7). With regard to alterations in the expression of specific molecular markers, in certain cases localized in areas that exhibit the chromosomal aberrations described, the estrogen receptor (ER) must be considered. Not all precursor lesions show a positivity for $\mathrm{ER}$, but in the majority of cases, its presence is an important risk factor, particularly if associated to the Ki67 expression, 

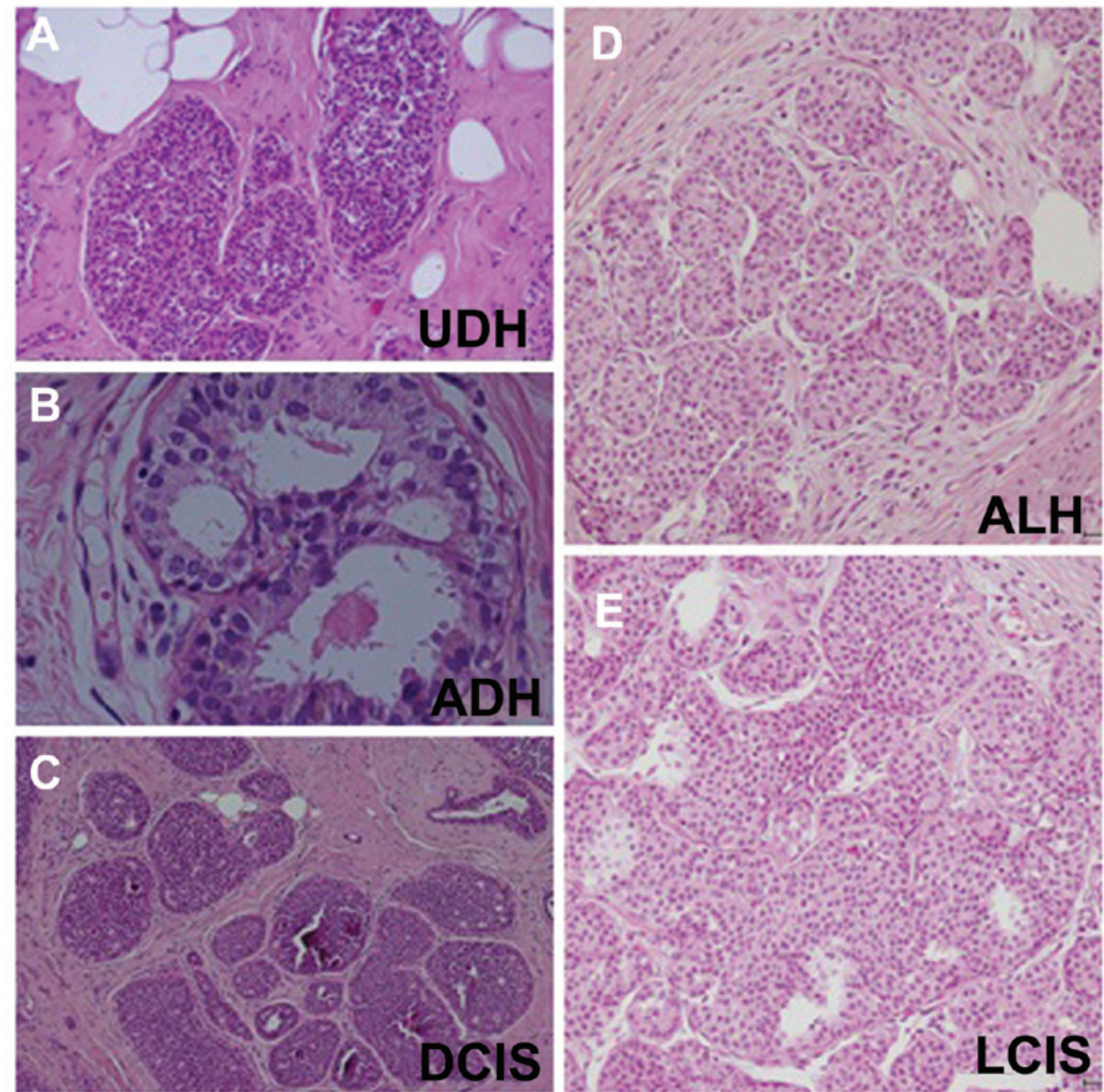

Figure 1. Hematoxylin and eosin (H/E) representation of breast cancer (BC) precursor progression. Ductal precursors: (A) UDH, (B) ADH and (C) DCIS Lobular precursors: (D) ALH and (E) LCIS (magnification, x20). UDH, usual ductal hyperplasia; ADH, atypical ductal hyperplasia; DCIS, ductal carcinoma in situ; ALH, atypical lobular hyperplasia; LCIS, lobular carcinoma in situ.

as in DCIS (8). By contrast, ER $\beta$ expression is decreased during the supposed precursor lesion progression steps (9). In addition, progesterone receptor expression represents a marker of progression, particularly if associated with ER positivity. Furthermore, its expression appears to correlate with histological grade, but not to the prognosis of IDC patients (10).

With regard to HER-2/c-erb2, hyperexpression/amplification has been detected in ADH and in 25\% of LCIS cases if associated with invasive components (11). In addition, the aberrant expression of various molecules of the cell cycle, including p21, p27 and p16, has been identified in $\mathrm{BC}$ precursor lesions (12). An additional molecular marker associated with $\mathrm{BC}$ progression is $\mathrm{Bcl}-2$. In particular, its expression decreases gradually during the steps of $\mathrm{BC}$ tumor evolution and its negativity has been associated with poor prognosis (13). Moreover, Bcl-2 positivity has been identified to correlate with p53 negativity in normal breast tissue and several $\mathrm{BC}$ precursor lesions (14). Bcl-2 expression is often also associated with Ki67 expression, in fact, high Ki67 expression, associated with negativity for Bcl-2, has been reported to correlate with the development of poorly-differentiated carcinoma. By contrast, alterations in $\mathrm{p} 53$, well described in invasive $\mathrm{BCs}$, are present in DCIS only (15).
E-cadherin is a molecular marker that is well characterized in $\mathrm{BC}$ precursor lesions, mainly as it is located in the $16 \mathrm{q}$ chromosomal region where losses are commonly described (16).

Finally, epigenetic modifications have been reported to be associated with $\mathrm{BC}$ precursor lesions, in particular, gene methylation. E-cadherin hypermethylation has been highlighted in DCIS and the methylation pattern of this gene is consistent with the hypothesis that DCIS represents an IDC precursor (17).

\section{Conclusions}

Molecular techniques, including DNA microarrays, immunohistochemistry and cytogenetic analysis, have made a significant contribution, in a number of cases, to the definition of specific molecular alterations that are common to several lesions at a 'high risk' of evolution (18).

However, cellular models suitable for functional studies on the molecular alterations identified, are extremely limited and not representative of the numerous preinvasive/precursors lesions of BC. Furthermore, in the majority of cases, the variable molecular signatures of precancerous lesions are not associated with transformation to the invasive phenotype (3). 
Therefore, the specific and defined molecular steps are not necessarily identified.

Thus, the existence of a multistep process of evolution of BC precursors lesions remains unknown, preventing the assignment of valid prognostic value to the molecular alterations associated.

\section{References}

1. Lopez-Garcia MA, Geyer FC, Lacroix-Triki M, Marchió C and Reis-Filho JS: Breast cancer precursors revisited: molecular features and progression pathways. Histopathology 57: 171-192, 2010.

2. Gong G, DeVries S, Chew KL, Cha I,Ljung BM and Waldman FM Genetic changes in paired atypical and usual ductal hyperplasia of the breast by comparative genomic hybridization. Clin Cancer Res 7: 2410-2414, 2001

3. Pinder SE and Ellis IO: The diagnosis and management of pre-invasive breast disease: ductal carcinoma in situ (DCIS) and atypical ductal hyperplasia (ADH)-current definitions and classification. Breast Cancer Res 5: 254-257, 2003.

4. Simpson PT, Gale T, Reis-Filho JS, Jones C, Parry S, Sloane JP, Hanby A, Pinder SE, Lee AH, Humphreys S, Ellis IO and Lakhani SR: Columnar cell lesions of the breast: the missing link in breast cancer progression? A morphological and molecular analysis. Am J Surg Pathol 29: 734-746, 2005.

5. Simpson PT, Reis-Filho JS, Gale T and Lakhani SR: Molecular evolution of breast cancer. J Pathol 205: 248-254, 2005.

6. Mastracci TL, Shadeo A, Colby SM, Tuck AB, O'Malley FP, Bull SB, Lam WL and Andrulis IL: Genomic alterations in lobular neoplasia: a microarray comparative genomic hybridization signature for early neoplastic proliferation in the breast. Genes Chromosomes Cancer 45: 1007-1017, 2006.

7. Amari M, Suzuki A, Moriya T, Yoshinaga K, Amano G, Sasano H, Ohuchi N, Satomi S and Horii A: LOH analyses of premalignant and malignant lesions of human breast: frequent $\mathrm{LOH}$ in $8 \mathrm{p}, 16 \mathrm{q}$, and $17 \mathrm{q}$ in atypical ductal hyperplasia. Oncol Rep 6: 1277-1280, 1999.

8. Iqbal M, Davies MP, Shoker BS, Jarvis C, Sibson DR and Sloane JP: Subgroups of non-atypical hyperplasia of breast defined by proliferation of oestrogen receptor-positive cells. J Pathol 193: 333-338, 2001.
9. Shaaban AM, O'Neill PA, Davies MP, Sibson R, West CR, Smith PH and Foster CS: Declining estrogen receptor-beta expression defines malignant progression of human breast neoplasia. Am J Surg Pathol 27: 1502-1512, 2003.

10. Ariga N, Suzuki T, Moriya T, Kimura M, Inoue T, Ohuchi N and Sasano H: Progesterone receptor A and B isoforms in the human breast and its disorders. Jpn J Cancer Res 92: 302-308, 2001.

11. Mohsin SK, O'Connell P, Allred DC and Libby AL: Biomarker profile and genetic abnormalities in lobular carcinoma in situ. Breast Cancer Res Treat 90: 249-256, 2005.

12. Oh YL, Choi JS, Song SY, Ko YH, Han BK, Nam SJ and Yang JH: Expression of p21Waf1,p27Kip1 and cyclin D1 proteins in breast ductal carcinoma in situ: Relation with clinicopathologic characteristics and with p53 expression and estrogen receptor status. Pathol Int 51: 94-99, 2001.

13. Dawson SJ, Makretsov N, Blows FM, Driver KE, Provenzano E, Le Quesne J, Baglietto L, Severi G, Giles GG, McLean CA, Callagy G, Green AR, Ellis I, Gelmon K, Turashvili G, Leung S, Aparicio S, Huntsman D, Caldas C and Pharoah P: BCL2 in breast cancer: a favourable prognostic marker across molecular subtypes and independent of adjuvant therapy received. Br J Cancer 103: 668-675, 2010.

14. Siziopikou KP, Prioleau JE, Harris JR and Schnitt SJ: bcl-2 expression in the spectrum of preinvasive breast lesions. Cancer 77: 499-506, 1996.

15. Megha T, Ferrari F, Benvenuto A, Bellan C, Lalinga AV, Lazzi S, Bartolommei S, Cevenini G, Leoncini L and Tosi P: p53 mutation in breast cancer. Correlation with cell kinetics and cell of origin. J Clin Pathol 55: 461-466, 2002.

16. Zagouri F, Sergentanis TN and Zografos GC: Precursors and preinvasive lesions of the breast: the role of molecular prognostic markers in the diagnostic and therapeutic dilemma. World J Surg Oncol 5: 57, 2007.

17. Nass SJ, Herman JG, Gabrielson E, Iversen PW, Parl FF, Davidson NE and Graff JR: Aberrant methylation of the estrogen receptor and E-cadherin 5' $\mathrm{CpG}$ islands increases with malignant progression in human breast cancer. Cancer Res 60: 4346-4348, 2000.

18. Sen S and Hopwood V: Molecular cytogenetic evidence for multistep tumorigenesis: implications for risk assessment and early detection. Cancer Biomark 9: 113-132, 2010. 